\title{
MHTool Users Guide - Software for Manufactured Housing Structural Design
}

\author{
J.M. Lacy \\ W.D. Richins \\ July 2005
}

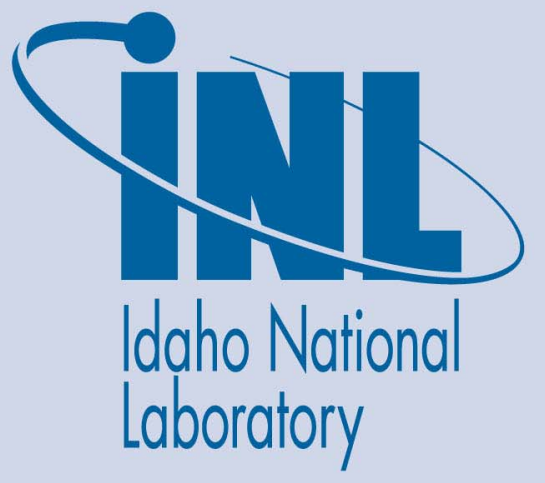

The INL is a U.S. Department of Energy National Laboratory operated by Battelle Energy Alliance 
INL/EXT-05-00356

\title{
MHTool Users Guide - Software for Manufactured Housing Structural Design
}

\author{
J.M. Lacy \\ W.D. Richins
}

July 2005

\begin{abstract}
Idaho National Laboratory
Idaho Falls, Idaho 83415
\end{abstract}

Prepared for the

U.S. Department of Housing and Urban Development

Interagency Agreement I-OPC-22618 and the

U.S. Department of Energy

Under DOE Idaho Operations Office

Contract DE-AC07-05ID14517 


\section{CONTENTS}

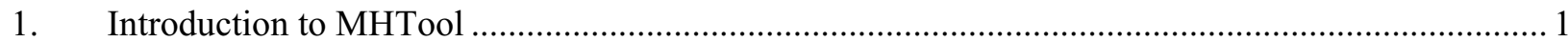

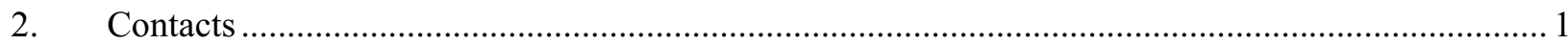

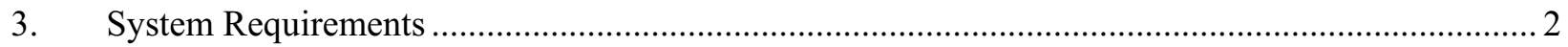

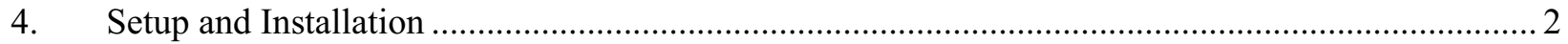

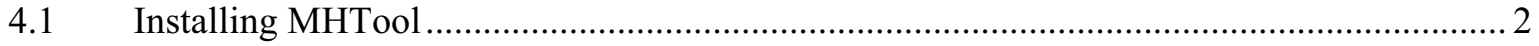

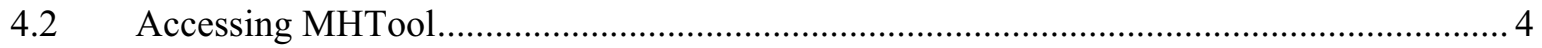

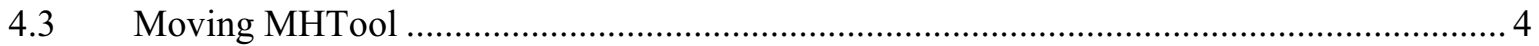

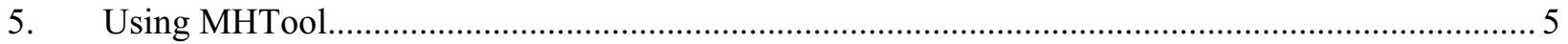

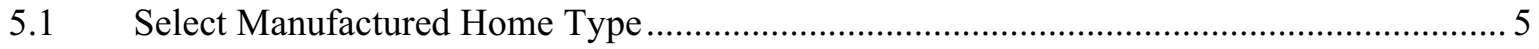

5.2 Modify Overall Home Dimensions …..................................................................... 5

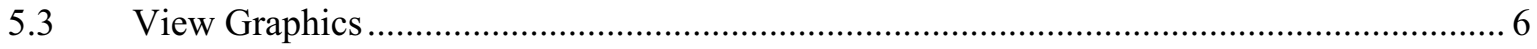

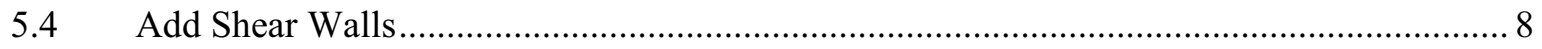

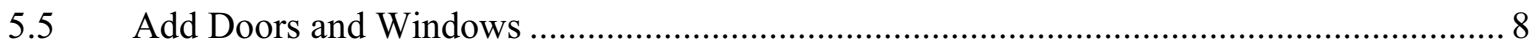

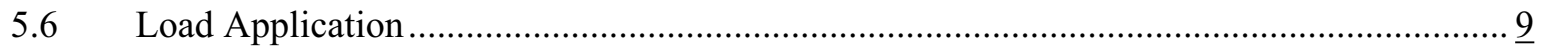

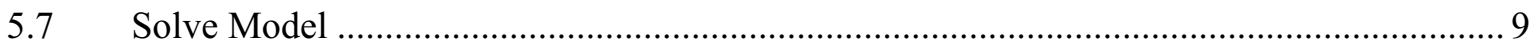

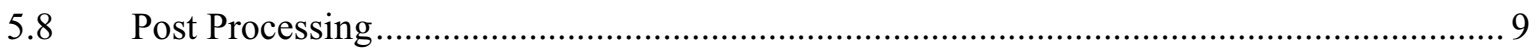

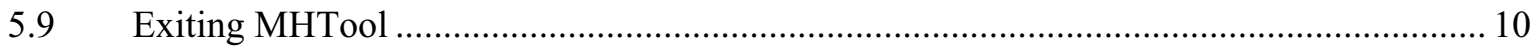

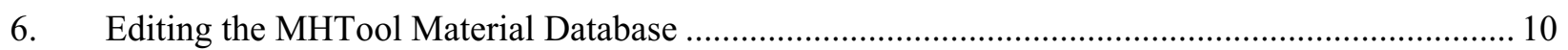

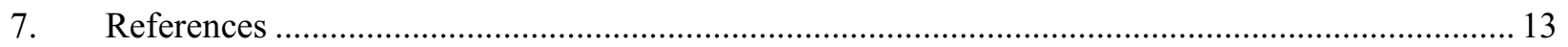




\section{MHTool Users Guide -}

\section{Software for Manufactured Housing Structural Design}

\section{Introduction to MHTool}

Since the late 1990s, the Department of Energy's Idaho National Laboratory (INL) has worked with the US Department of Housing and Urban Development (HUD), the Manufactured Housing Institute (MHI), the National Institute of Standards and Technology (NIST), the National Science Foundation (NSF), and an industry committee to measure the response of manufactured housing to both artificial and natural wind loads and to develop a computational desktop tool to optimize the structural performance of manufactured housing to HUD Code loads. MHTool is the result of an 8-year intensive testing and verification effort using single and double section homes.

MHTool is the first fully integrated structural analysis software package specifically designed for manufactured housing. To use MHTool, industry design engineers will enter information (geometries, materials, connection types, etc.) describing the structure of a manufactured home, creating a base model. Windows, doors, and interior walls can be added to the initial design. Engineers will input the loads required by the HUD Code (wind, snow loads, interior live loads, etc.) and run an embedded finite element solver to find walls or connections where stresses are either excessive or very low. The designer could, for example, substitute a less expensive and easier to install connection in areas with very low stress, then re-run the analysis for verification. If forces and stresses are still within HUD Code requirements, construction costs would be saved without sacrificing quality. Manufacturers can easily change geometries or component properties to optimize designs of various floor plans then submit MHTool input and output in place of calculations for DAPIA review. No change in the regulatory process is anticipated.

MHTool, while not yet complete, is now ready for demonstration. The pre-BETA version (Build-16) was displayed at the 2005 National Congress \& Expo for Manufactured \& Modular Housing. Additional base models and an extensive material library need to be developed. Output displays and listings will need to be expanded and model checking capability added. When completed, MHTool will ultimately lead to new manufactured housing designs that meet or exceed the HUD Code for quality, durability, and safety while reducing labor and materials. This will reduce cost and increase home ownership for the traditional manufactured housing market of first time or low-income buyers.

MHTool uses the freeware solver FElt modified specifically for manufactured housing by researchers at Washington State University and INL. Input data, material properties, and results verification are based on full scale testing conducted by INL and others. See Section 7 for a collection of references.

\section{Contacts}

Project Manager: Bill Richins, 208-526-0522

MHTool Software Development: Jeff Lacy, 208-526-2788

Business Development: John Snyder, 208-526-9812 


\section{System Requirements}

MHTool was developed on Pentium 4 machines running Windows XP Professional. A minimum processor speed of $1.5 \mathrm{GHz}, 512 \mathrm{MB}$ RAM, and $10 \mathrm{~GB}$ of available disk space is recommended. No additional non-standard software is required. A DELL Latitude D600 with a $1.8 \mathrm{GHz}$ Pentium M processor and 1GB RAM solves the current double-section home model in about 2.5 minutes.

\section{Setup and Installation}

\subsection{Installing MHTool}

It is strongly recommended that the user exit all Windows programs before installing MHTool.

1. Go to the MHTool Install CD and double-click on "setup.exe".

2. Follow instructions in the Installation Wizard.

If a previous version of MHTool is installed, the installation program will begin with the following screen. Select "Next" to continue with the setup process.

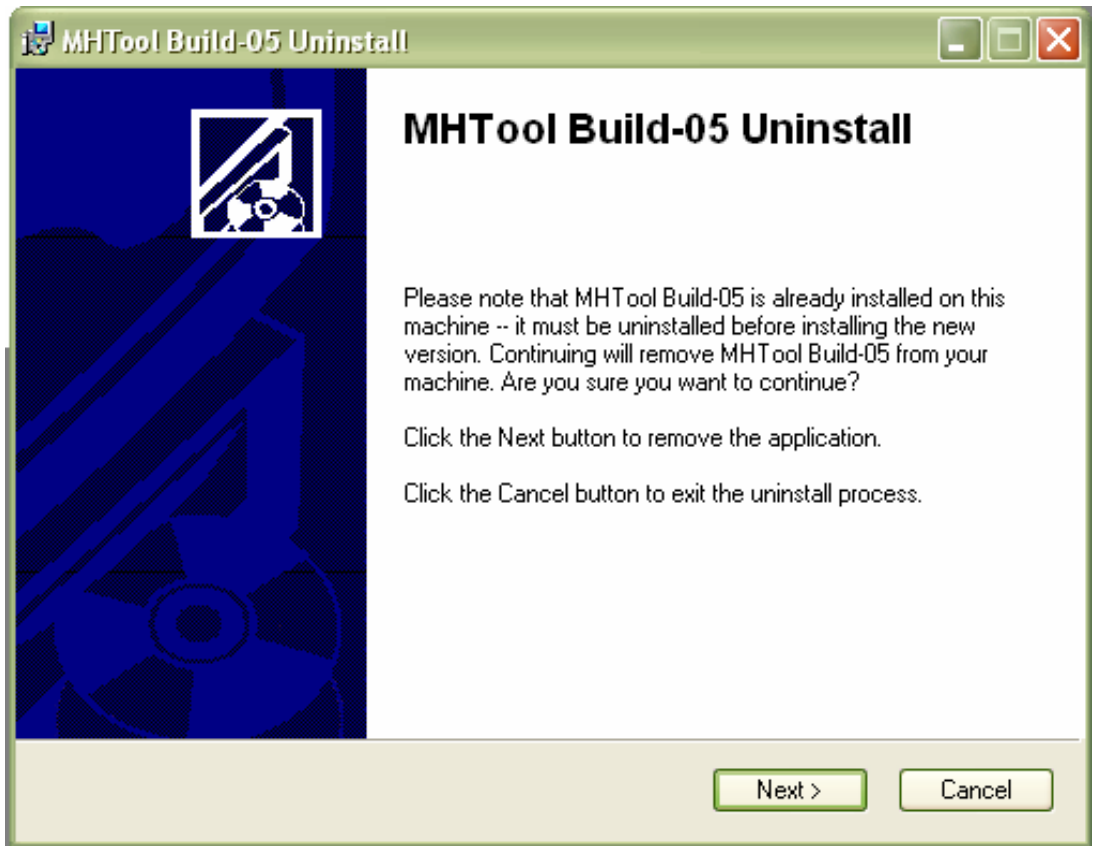

The next screen allows the user to choose a directory where MHTool installs. To install in the default directory (recommended) select "Next", otherwise select the "Browse" button and select another install directory. 


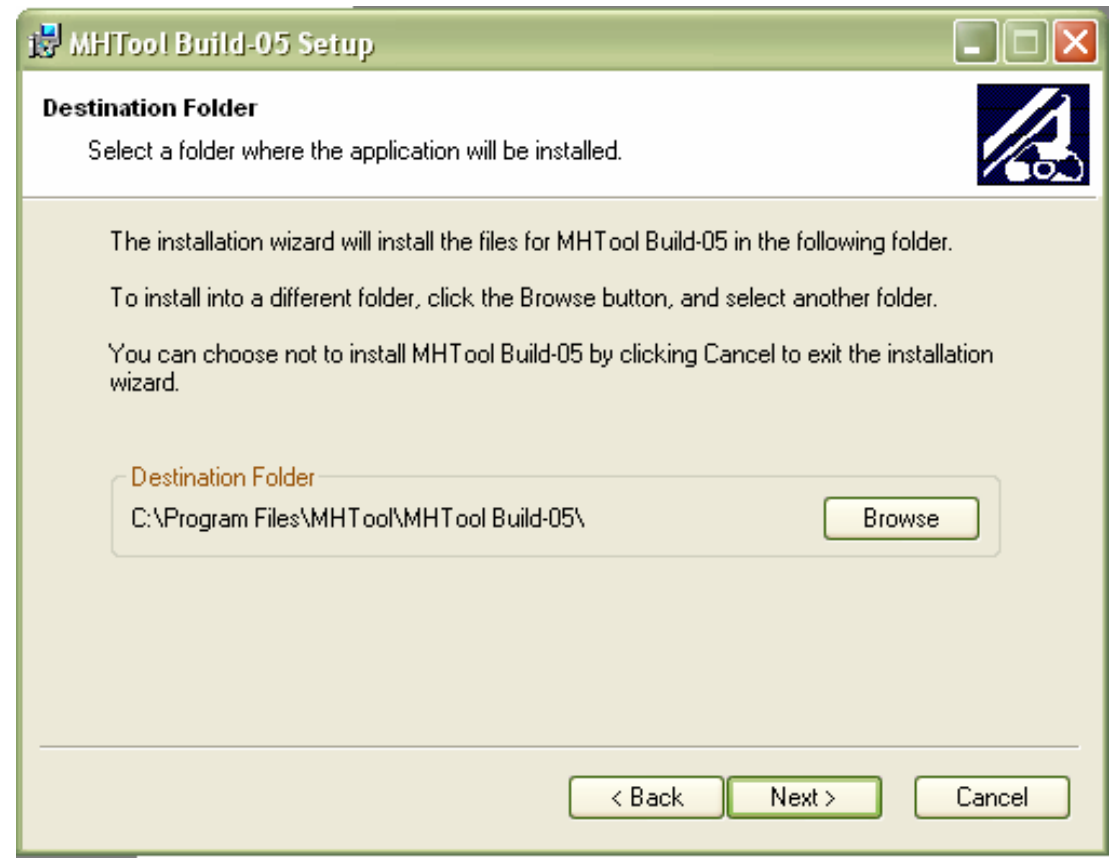

The next screen confirms installation of the program. Click "Next" to begin installation.

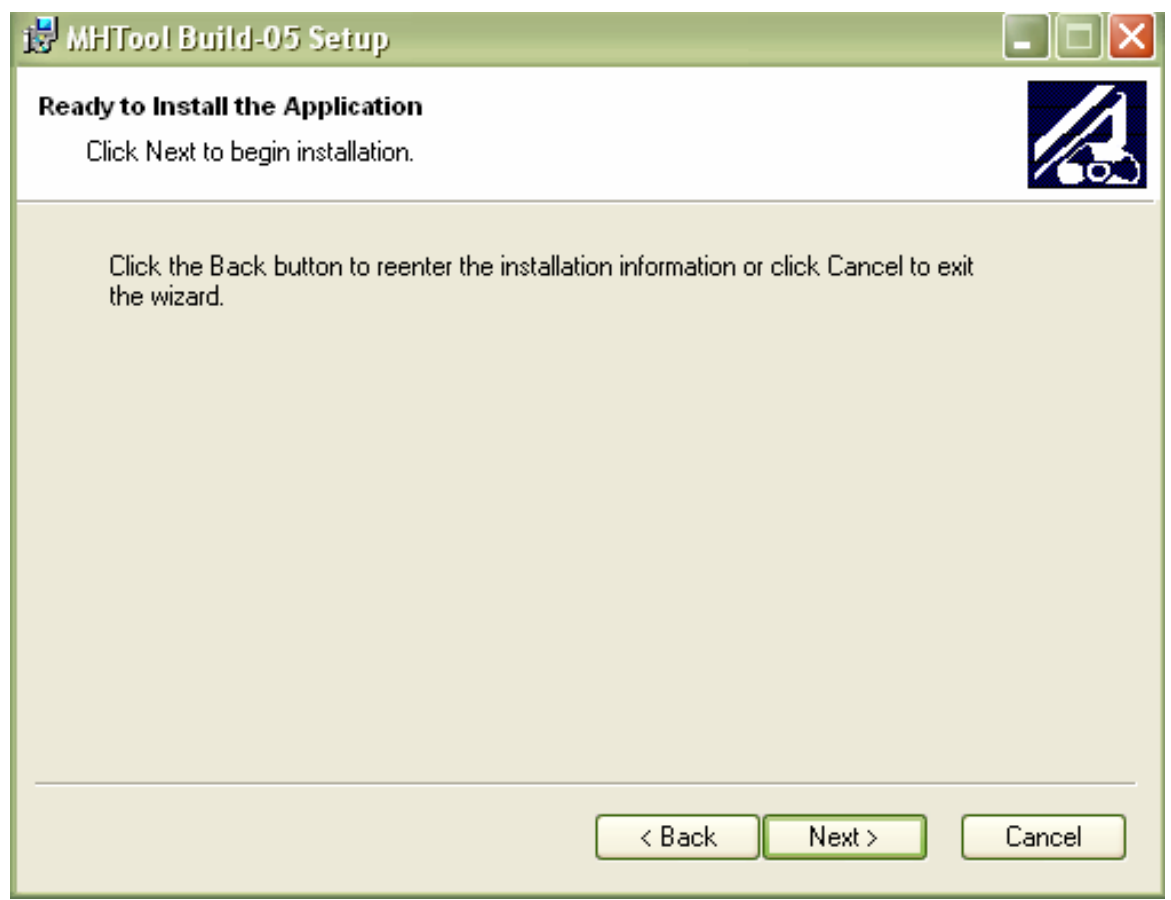

It may take a few minutes for the program to install. Once MHTool has finished installing, the user will receive the following message. The user has successfully installed MHTool. 


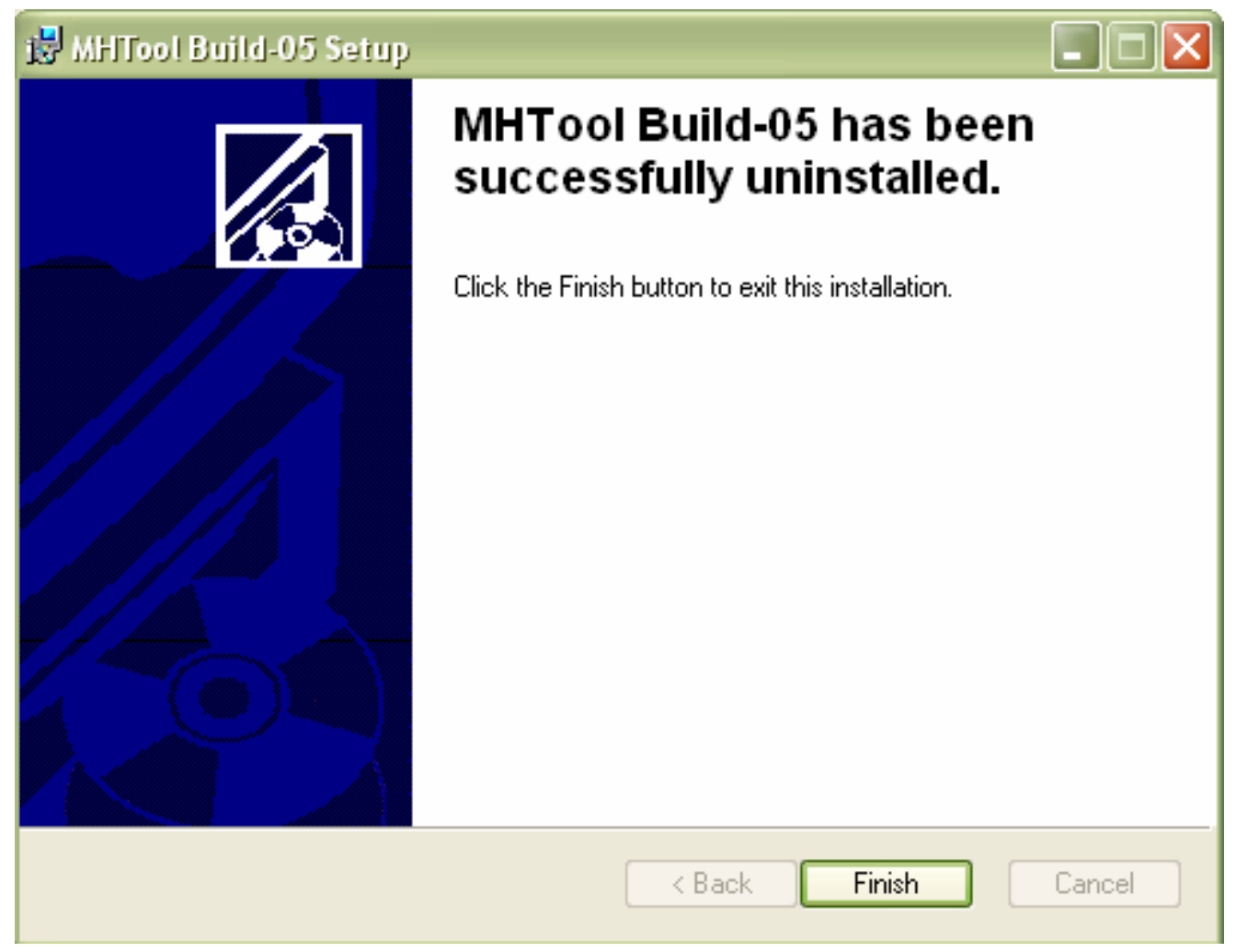

\subsection{Accessing MHTool}

To access the program once it has been installed, go to the Start Menu then select Programs $\rightarrow$ MHTool $\rightarrow$ MHTool Build-16 (if, for example, the installed version is Build-16).

\subsection{Removing MHTool}

To remove MHTool, use the "Add/Remove programs" option in Windows. Go to the Control Panel (start menu $\rightarrow$ Settings $\rightarrow$ Control Panel) and select "Add or Remove Programs." Select the MHTool program and click the "Remove" button. 


\section{Using MHTool}

\subsection{Select Manufactured Home Type}

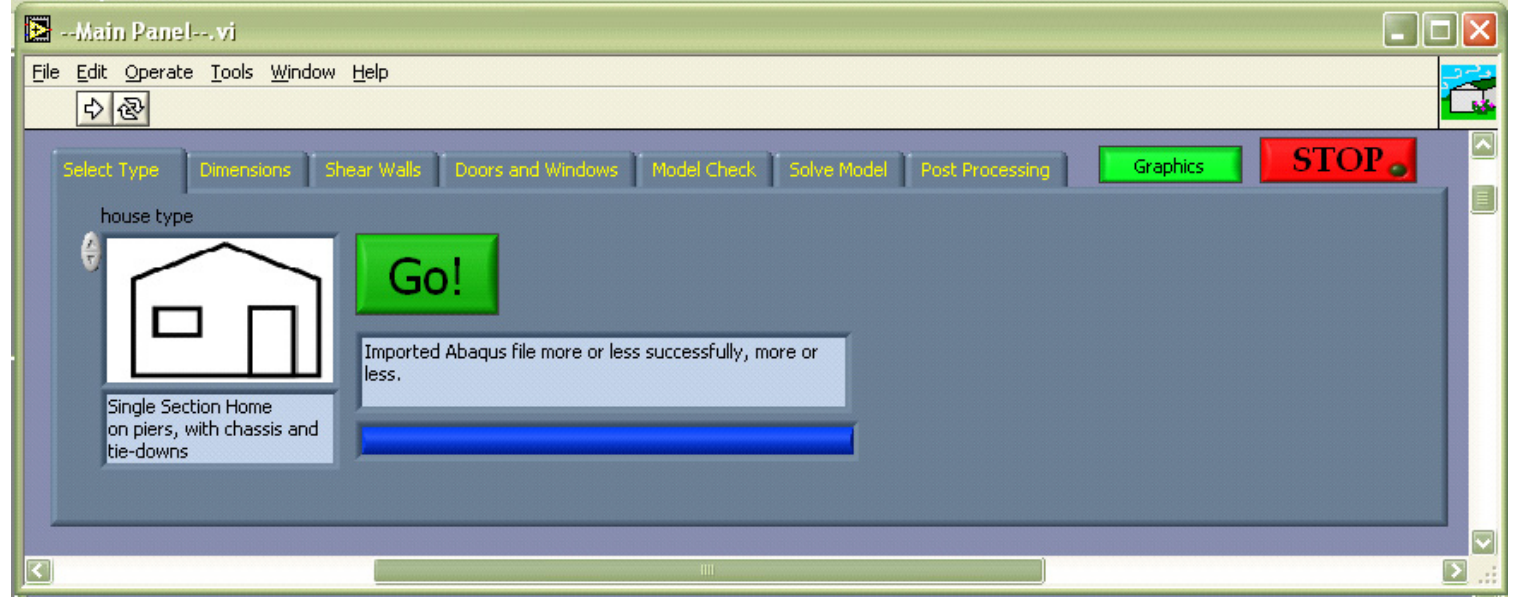

The first screen displayed allows the user to select the manufactured home type. Currently, models of typical single-section and double-section homes are available. Other standard models are planned. The user can also import a model from a file (this option not implemented in Build-16). By using the up arrow or clicking on the home icon, select the home type then press the "Go!" button. Note: the tabs are for programmer use only.

\subsection{Modify Overall Home Dimensions}

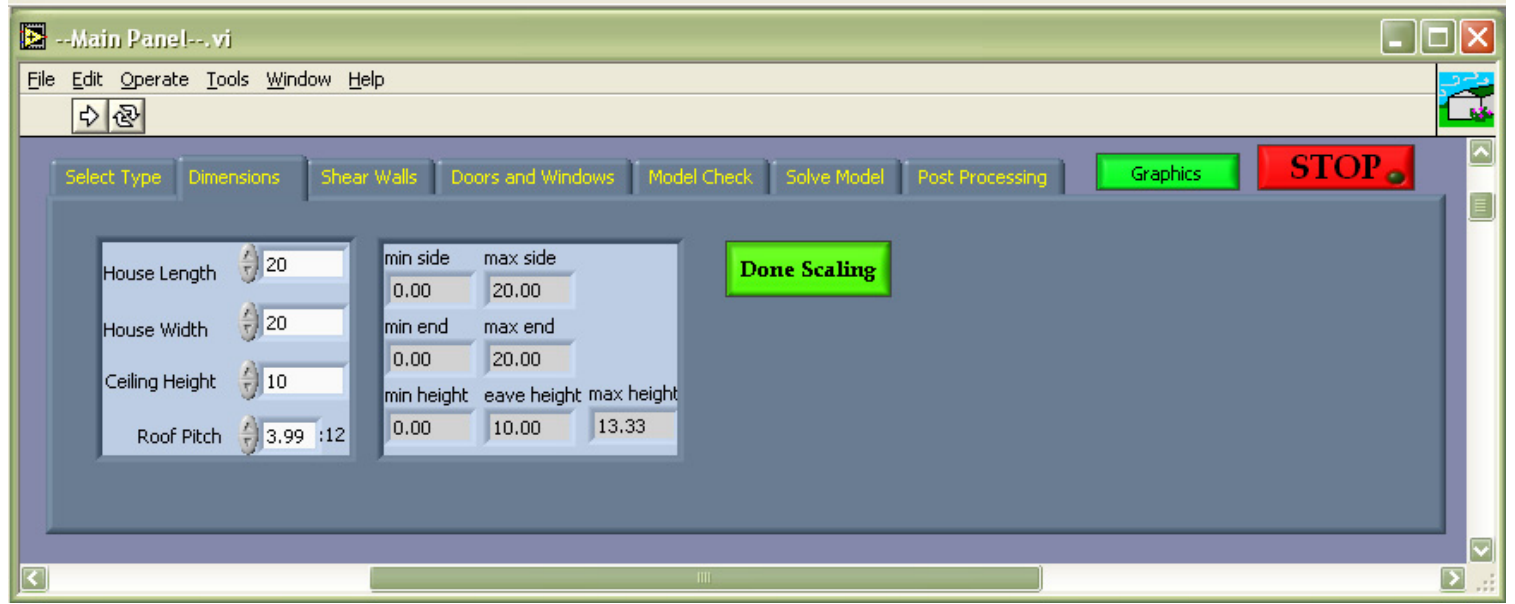

Next, customize the home dimensions. Change the home length, width, ceiling height, and roof pitch as necessary by either typing in values or using the up/down arrows.. The second box next to the input selection is for programmer use only. Once dimensions are complete, click "Done Scaling". 


\subsection{View Graphics}

Model graphics are available at anytime after the initial home type has been selected. Click on the green GRAPHICS button to open the MHTool graphics display. The graphics display has nine basic functions; roll, vertical, horizontal, spin, zoom perspective, visibility, select elements, and reset graph.

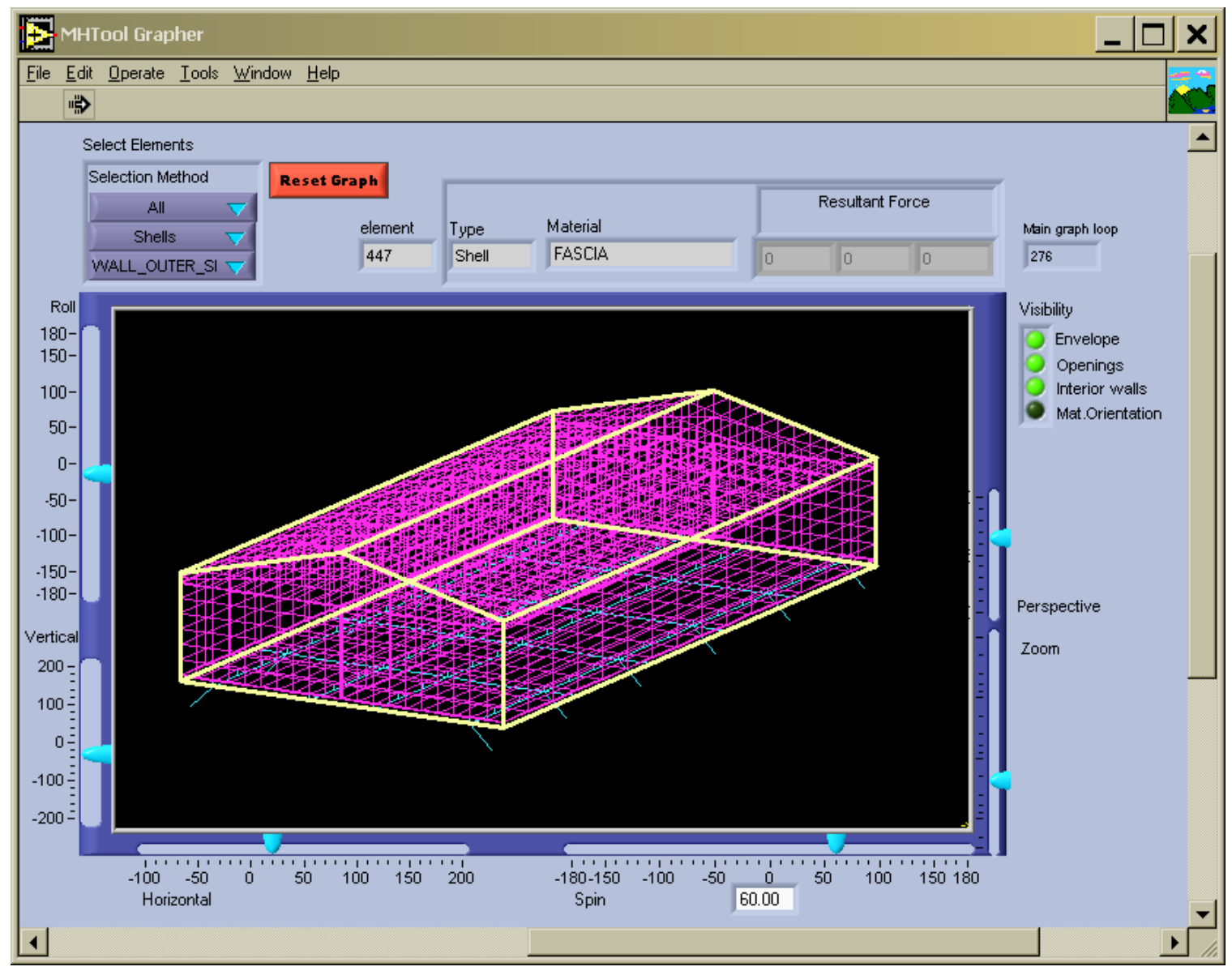

A. Roll: The Roll scroll bar allows the user to rotate the structural model along an axis parallel to a horizontal line running along the length of the structure. The roll scroll bar moved in an upward direction rotates the model counterclockwise.

B. Vertical: The Vertical scroll bar allows the user to move the model up and down.

If the scroll bar is moved up or down excessively, the model may disappear from the screen. To fix the problem, move the vertical scroll bar to the center position, then try moving the scroll bar in smaller increments.

C. Horizontal: The Horizontal bar allows the user to move the model left and right.

If the scroll bar is moved left or right excessively, the model will seem to have disappeared. To fix the problem, move the vertical scroll bar to the center position, then try moving the scroll bar in smaller increments. 
D. Spin: The Spin scroll bar allows the user to rotate the model along an axis parallel to the vertical line. The spin scroll bar moved to the left will rotate the model in the left direction.

E. Zoom: The Zoom scroll bar allows the user to adjust the view magnification (zoom) in or out. Moving the zoom scroll bar down will zoom in.

If the scroll bar is moved up or down excessively, the model may disappear. To fix the problem, move the scroll bar to the center position, then try moving the scroll bar in smaller increments

F. Perspective: The Perspective scroll bar allows the user to see how the model would appear at different distances from the object. Moving the scroll bar up will make the structural drawing appear farther from the object.

If the scroll bar is moved down excessively, the model will appear extremely distorted and chaotic. To fix the problem, move the scroll bar to the center position, then try moving the scroll bar in smaller increments

G. Visibility: Visibility is controlled by on and off toggle switches as follows:

1) Envelope - basic outline of the model

2) Openings - windows, doors

3) Interior walls - shear and partition walls

4) Mat. Orientation - not yet fully implemented

5) Loads - not yet available

If all of the toggle switches are off, no model will appear

H. Reset Graphics: Redraws the graphics.

I. Select Elements: Selects the element types, materials, or model region to be displayed. 


\subsection{Add Shear Walls}

The next screen defines interior shear wall location, width, and construction. Since the strength of partition walls is not considered in the structural analysis of manufacture homes to the HUD Code, they are not currently modeled in MHTool. Shear walls can be defined as full width, half-width, or customwidth.

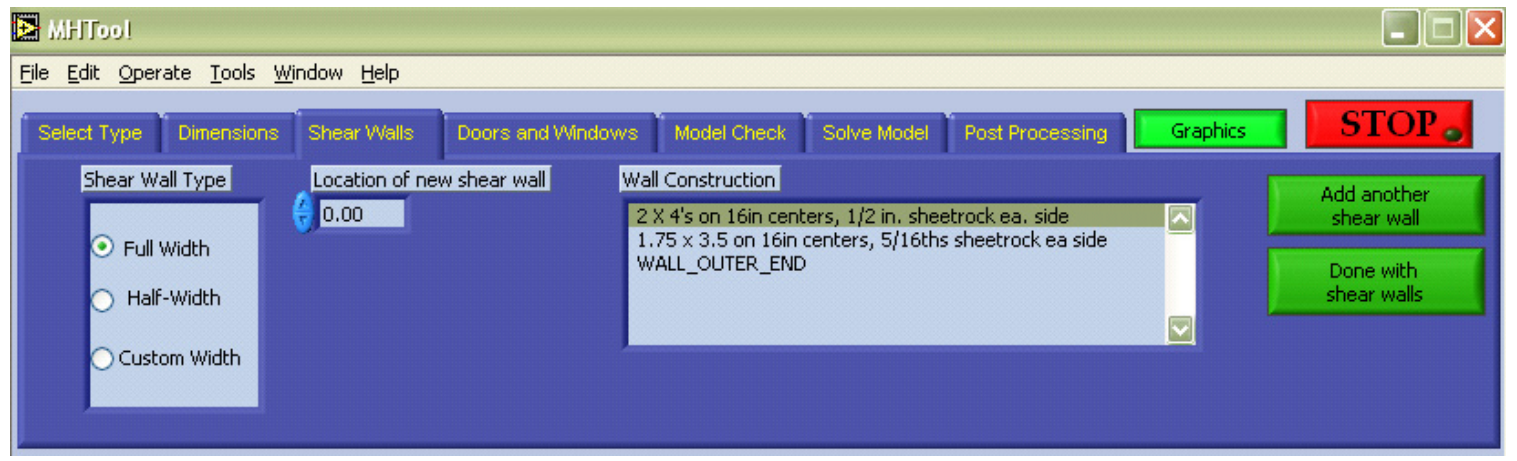

Define a shear wall by entering the width type, location (identify the distance along the length of the home and which side if not full width), and wall construction. Shear walls created will be visible in the MHTool graphics if the "Interior Walls" visibility button is on. Continue adding shear walls using the "Add another shear wall" button until complete. Next, press "Done with shear walls" to move to the next MHTool section.

\subsection{Add Doors and Windows}

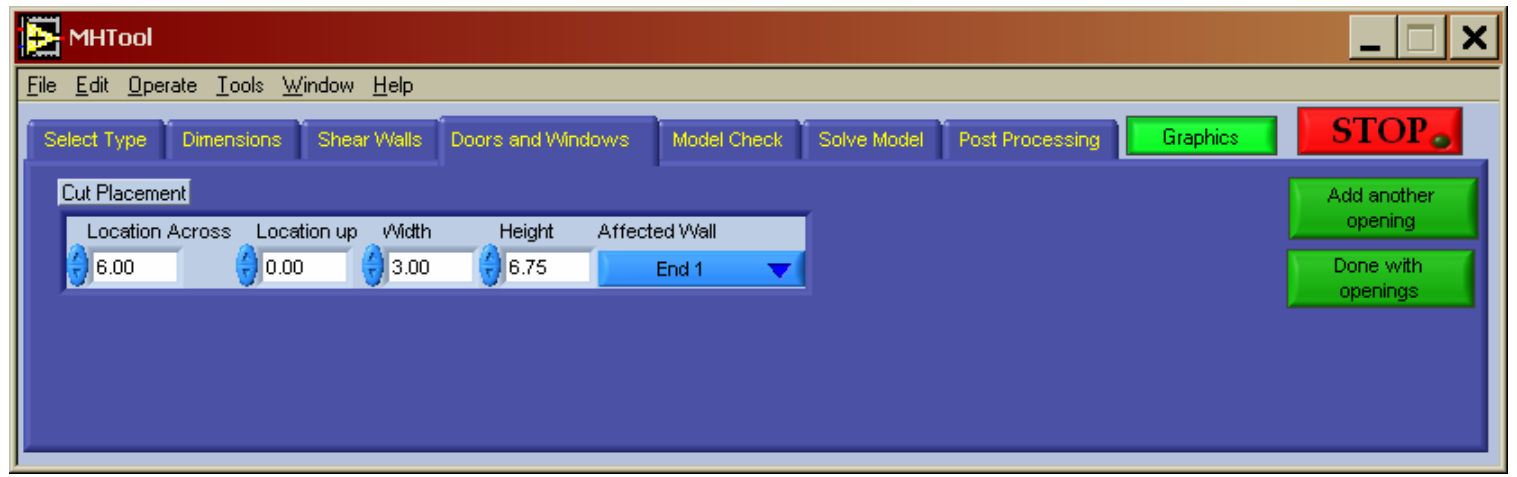

This section of MHTool creates openings (windows and doors) in the exterior end and side walls of the manufactured home model. The ability to create openings within interior shear walls has not yet been implemented. Material properties are automatically adjusted within these openings to account for the near zero equivalent structural strength. First select the affected wall, then enter location and dimensions. Openings will be visible in the MHTool graphics if the "Openings" visibility button is on. Continue adding openings using the "Add another opening" button until complete. Next, press "Done with openings" to move to the next MHTool section. 


\subsection{Load Application}

MHTool applies loads automatically to the home. No user input is required. Currently one load set is applied, consisting of a $30 \mathrm{psf}$ lateral load on one long wall, combined with gravity on all elements of the home. Pressure and gravity forces are automatically scaled with the user-selected home dimensions. Future releases will incorporate additional loads and load combinations, along with the ability to accept user-defined loads and load combinations; these features are not implemented in the current release.

\subsection{Solve Model}

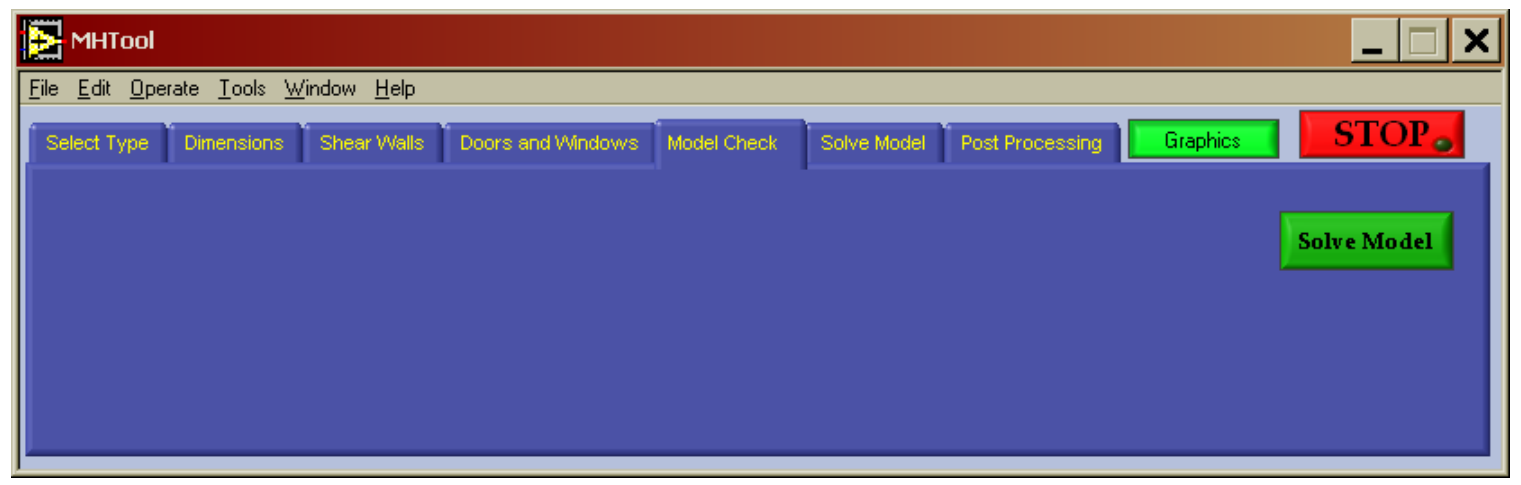

Click on the "Solve Model" button. A DOS command window will be displayed during the solution process for 1-5 minutes depending on model complexity and computer processor speed.

\subsection{Post Processing}

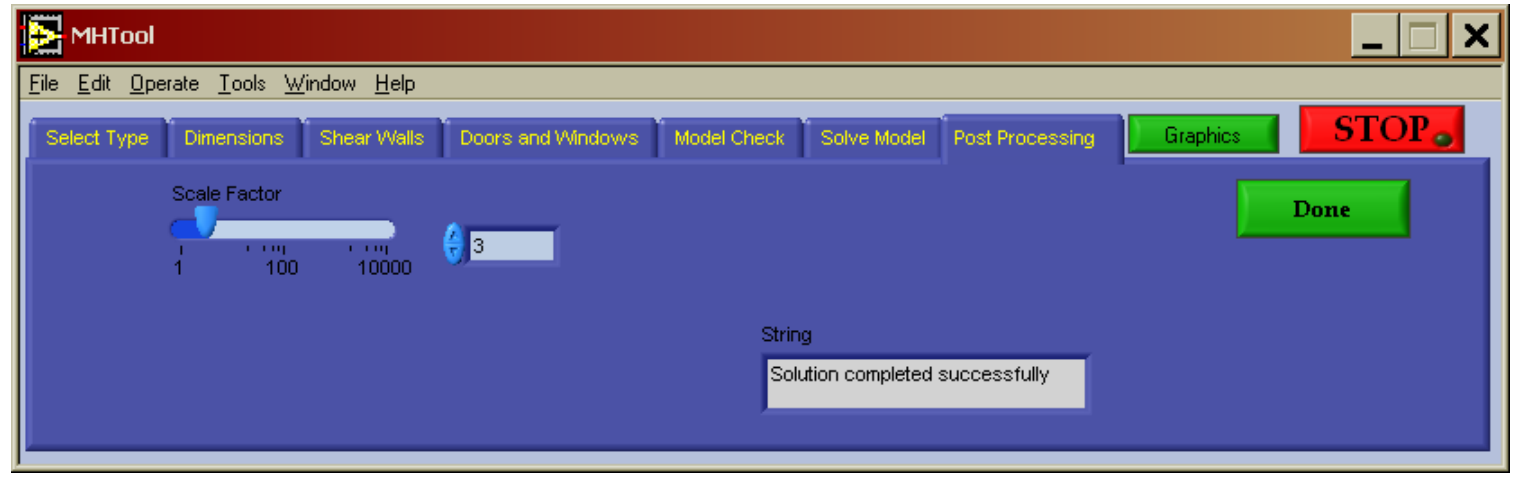

After the DOS command screen has closed the window above will appear indicating that the model solved successfully. Forces between significant interfaces (wall to roof, across marriage line, floor to wall, etc.) may be investigated by moving the cursor over the interface location of interest (see window below). Displacements can be viewed by adjusting the scale factor and turning on and off the appropriate elements. Post-processing of forces in the chassis and stresses in the wall elements has not yet been implemented. 


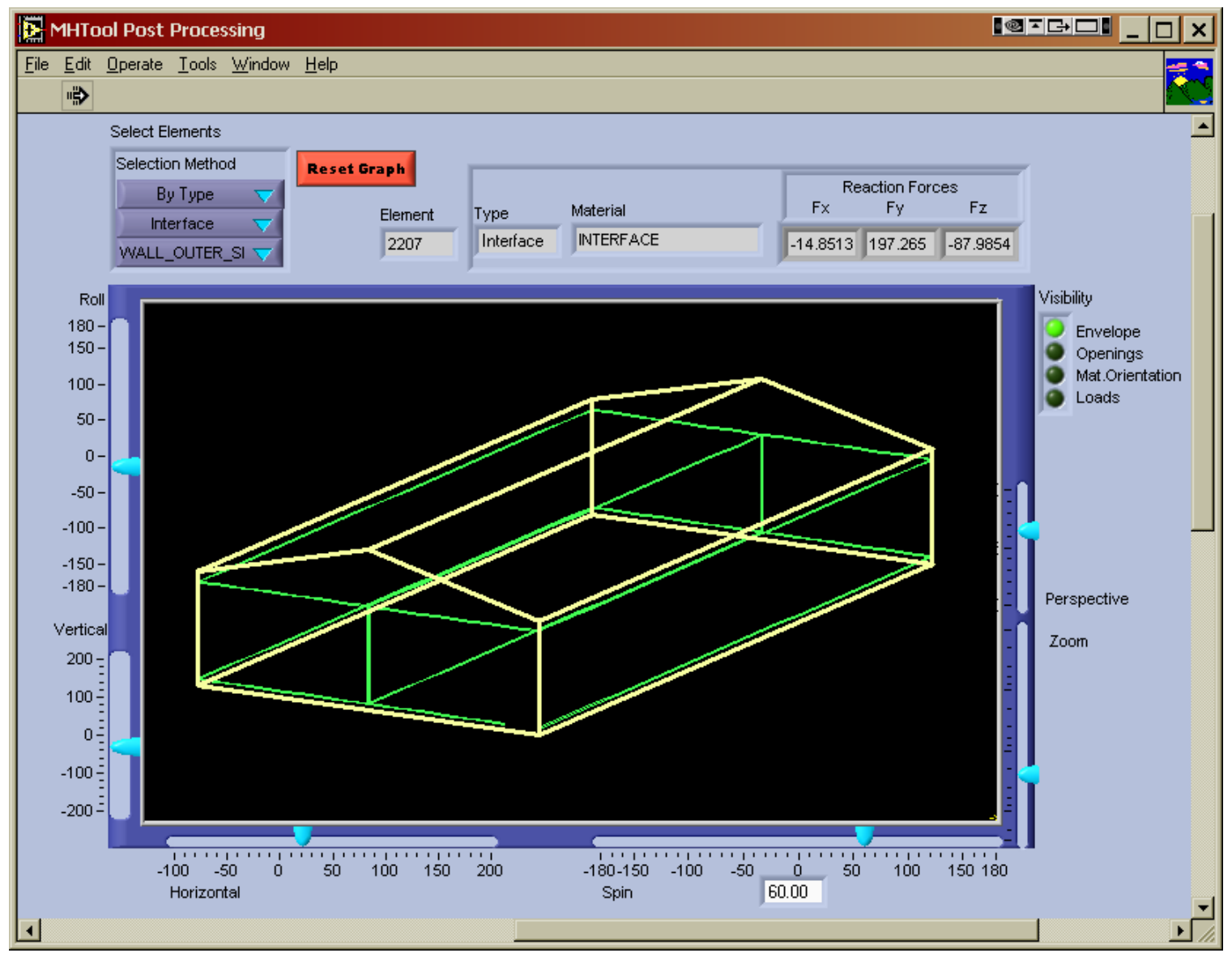

\subsection{Exiting MHTool}

MHTool program should be exited by selecting the "File" drop down menu and then selecting "Exit". The program will close automatically. Model saving capability has not yet been implemented. Restart MHTool to evaluate the next manufactured home design.

\section{Editing the MHTool Material Database}

MHTool utilizes a database with structural properties of the different materials used in the construction of a manufactured home. Examples of the various material types include exterior wall panels, chassis main and secondary beams, floor panels, roof trusses, etc. The current version only includes default values for these properties, which must be modified by the user to reflect the materials used in the particular home style being investigated.

The material database is a text file called MatLib.txt in the \Data subdirectory of the MHTool installation directory ( e.g. C:IProgram Files $\backslash$ MHTool $\backslash M H T o o l ~ B u i l d-16 \backslash$ data $\backslash$ MatLib.txt). This file may be edited by the user using any common text editor such as Notepad or Wordpad, then saved as an unformatted text file. 
A copy of the default MatLib.txt file is presented below. The material properties listed follow the naming and syntax requirements of the FElt finite element solver embedded in MHTool. MHTool has the ability to convert input material units to consistent MKS units for model solution, so units may be mixed in the material library. However, units must be provided for all non-unitless quantities. See the FElt User's Manual for individual material property descriptions.

Felt Translator Material Library

Format:

1st line: *Property_Name

2-nth lines: comma delimited list of properties, assigned with '=' sign, with units after value.

Acceptable units: (note that there are no periods(.) in units

in ft mm cm m in^2 $\mathrm{ft}^{\wedge} 2 \mathrm{~mm}^{\wedge} 2 \mathrm{~cm}^{\wedge} 2 \mathrm{~m}^{\wedge} 2 \mathrm{in}^{\wedge} 3 \mathrm{ft}^{\wedge} 3 \mathrm{~mm}^{\wedge} 3 \mathrm{~cm}^{\wedge} 3 \mathrm{~m}^{\wedge} 3 \mathrm{in}^{\wedge} 4 \mathrm{ft}^{\wedge} 4 \mathrm{~mm}^{\wedge} 4 \mathrm{~cm}^{\wedge} 4 \mathrm{~m}^{\wedge} 4$

psi lb/in^2 Pa kPa MPa pci lb/in^3 pcf lb/ft^3 kg/m^3 g/cc g/ml

All units are converted to consistent units for use in the felt model.

Example

*NULL 1

$\mathrm{E}=1.0 \mathrm{E}+7 \mathrm{psi}, \mathrm{t}=0.1667 \mathrm{ft}$, $\mathrm{rho}=10 \mathrm{~g} / \mathrm{cc}, \mathrm{nu}=.29$

etc..

etc..

*NULL_2

etc...

etc...

${ }^{*}$ CEILING

$E=34074 p s i, J=92647 p s i, G=7700 p s i, R m=10000 p s i, R k=10000 p s i, n u=0.28, r h o=0.28, t=4.25 i n, c=0, K z=-0.01$

${ }^{*}$ CHASSIS MAIN

$E=30.0 E+6 p s i, A=1.98 \mathrm{in}^{\wedge} 2, \mathrm{ly}=1.06 \mathrm{in} \wedge 4, \mathrm{Iz}=42.23 \mathrm{in}^{\wedge} 4, \mathrm{~J}=0.007 \mathrm{in}^{\wedge} 4$,

$\mathrm{G}=11.5 \mathrm{E}+6 \mathrm{psi}$ nu $=.30$, rho $=35.0 \mathrm{pcf}$

${ }^{*}$ CHASSIS_PURLIN

$E=30.0 E+6 p s i, A=1.98 \mathrm{in}^{\wedge} 2, \mathrm{ly}=1.06 \mathrm{in}^{\wedge} 4, \mathrm{Iz}=42.23 \mathrm{in}^{\wedge} 4, \mathrm{~J}=0.007 \mathrm{in}^{\wedge} 4$,

$\mathrm{G}=11.5 \mathrm{E}+6 \mathrm{psi}$ nu=.30, rho=35.0pcf

*Door_Window

$E=3407.4 p s i, J=9264.7 p s i, G=770.0 p s i, R m=1000.0 p s i, R k=1000.0 p s i, n u=0.28$, rho=0.28, t=4.25in, $c=0, K z=-0.01$

${ }^{*} \mathrm{FASCIA}$

$E=34074 p s i, J=92647 p s i, G=7700 p s i, R m=10000 p s i, R k=10000 p s i, n u=0.28$, rho=0.28, t=4.25in, c=0, Kz=-0.01

${ }^{*}$ FLOOR_C

$E=34074 p s i, J=92647 p s i, G=7700 p s i, R m=10000 p s i, R k=10000 p s i, n u=0.28$, rho=0.28, t=4.25in, $c=0, K z=-0.01$

${ }^{*}$ FLOOR JOIST

$\mathrm{E}=1.2 \mathrm{E}+6 \mathrm{psi}, \mathrm{A}=13.875 \mathrm{in}^{\wedge} 2, \mathrm{ly}=2.60 \mathrm{in} \wedge 4, \mathrm{Iz}=98.9 \mathrm{in}^{\wedge} 4, \mathrm{~J}=9.34 \mathrm{in}^{\wedge} 4$,

$\mathrm{G}=4.61 \mathrm{E}+5 \mathrm{psi}$ nu=.30, rho=35.0pcf

*INNER WALL 0

$E=3407 \overline{4}$ psi, J=92647psi, G=7700psi, Rm=10000psi, Rk=10000psi, nu=0.28, rho=0.28, $t=4.25 \mathrm{in}, \mathrm{c}=0, \mathrm{Kz}=-0.01$

*INNER_WALL_1

$E=3407 \overline{4}$ pi, $J=92647 p s i, G=7700 p s i, R m=10000 p s i, R k=10000 p s i, n u=0.28$, rho=0.28, $t=4.25 \mathrm{in}, c=0, K z=-0.01$

*INTERFACE

$I x=0.0, I y=1.0, I z=0.0, K x=10000000 ., K y=10000000 ., K z=10000000 ., c=10000000$.

*MATING WALL

$E=34074$ psi, J=92647psi, G=7700psi, Rm=10000psi, Rk=10000psi, nu=0.28, rho=0.28, t=4.25in, $c=0, K z=-0.01$

${ }^{*}$ RIDGE_BEAM

$E=34074$ psi, $J=92647 p s i, G=7700 p s i, R m=10000 p s i, R k=10000 p s i, n u=0.28$, rho=0.28, t=4.25in, $c=0, K z=-0.01$

${ }^{*}$ RIGID BEAM 
MHTool Users Guide

$E=30.0 E+7 p s i, A=1.98 i^{\wedge} 2, \quad l y=1.06 i n^{\wedge} 4, I z=42.23 i^{\wedge} 4, J=0.007 i n^{\wedge} 4$,

$\mathrm{G}=11.5 \mathrm{E}+7 \mathrm{psi} \mathrm{nu}=.30$, rho=35.0pcf

*SHEATHING

$\mathrm{E}=34074 \mathrm{psi}, \mathrm{J}=92647 \mathrm{psi}, \mathrm{G}=7700 \mathrm{psi}, \mathrm{Rm}=10000 \mathrm{psi}, \mathrm{Rk}=10000 \mathrm{psi}, \mathrm{nu}=0.28$, rho=0.28, $\mathrm{t}=4.25 \mathrm{in}, \mathrm{c}=0, \mathrm{Kz}=-0.01$

*TIE DOWN SPRING

$E=2 \overline{9}$ 5psi, $\overline{R k}=1000 p s i, A=1.0 i n^{\wedge} 2$

*TRUSS

$E=34074 p s i, J=92647 p s i, G=7700 p s i, R m=10000 p s i, R k=10000 p s i, n u=0.28$, rho=0.28, t=4.25in, $c=0, K z=-0.01$

*WALL_OUTER_END

$\mathrm{E}=34074 p s i, \mathrm{~J}=92647 \mathrm{psi}, \mathrm{G}=7700 \mathrm{psi}, \mathrm{Rm}=10000 \mathrm{psi}$, Rk=10000psi, nu=0.28, rho=0.28, t=4.25in, c=0, Kz=-0.01

*WALL OUTER SIDE

$\mathrm{E}=340 \overline{7} 4 \mathrm{psi}, \mathrm{J}=\overline{9} \mathbf{2 6 4 7 p s i}, \mathrm{G}=7700 \mathrm{psi}, \mathrm{Rm}=10000 \mathrm{psi}, \mathrm{Rk}=10000 \mathrm{psi}, \mathrm{nu}=0.28$, rho=0.28, t=4.25in, $\mathrm{c}=0, \mathrm{Kz}=-0.01$ 


\section{References}

Richins, W. D., Rahl, T. E., Lacy, J. M., Larson, T. K., Flood, M. N., Goodman, J. R., Schmidt, R. J., Koerner, B. D., Pandey, A. K., Stewart, A. H., and Walters, F. 1999, "Full-Scale Structural Testing of a Single-Wide Manufactured Home, Oakwood Model 1320; $13 \mathrm{ft}$ x 62ft" INEEL Test Report, INEEL/EXT1999-301, March 1999.

Richins, W. D., Lacy, J. M., Larson, T. K., Rahl, T. E., Goodman, J. R., Schmidt, R. J., Koerner, B. D., and Pandey, A. K. "Full-Scale Structural Testing of a Single-Wide Manufactured Home," Proceedings of the World Conference on Timber Engineering 2000, Whistler Resort, British Columbia, Canada, July 31 August 3, 2000.

Schmidt, R. J., Goodman, J. R., Richins, W. D., Pandey, A. K. 2000 "Improved Design of Manufactured Homes for Hazardous Winds," Proceedings of the World Conference on Timber Engineering 2000, Whistler Resort, British Columbia, Canada, July 31 - August 3, 2000.

Koerner, B. D., Schmidt, R. J., Goodman, J. R., and Richins, W. D. 2000 "Lateral Load Testing and Analysis of Manufactured Homes," Proceedings of the World Conference on Timber Engineering 2000, Whistler Resort, British Columbia, Canada, July 31 - August 3, 2000.

Richins, W. D., Larson, T. K., Schmidt, R. J., and Goodman, J. R., "Testing Manufactured Homes for High Winds," Proceedings of PATH Conference on Durability and Disaster Mitigation in Wood Frame Housing, Nov. 6 - 8, 2000, Madison, WI.

Koerner, B. D., "Methods for Manufactured Home Testing and Analysis," Univ. of Wyoming MS Thesis, 2000

Richins, W. D., Larson, T. K., O'Brien, C. C., "INEEL Manufactured Housing Project - Summary and Status,"2001 National Manufactured Housing Congress, Las Vegas, NV, April 17, 2001

Richins, W. D., Larson, T. K., Snow, S. D., Schmidt, R. J., Goodman, J. R., and Beaudoin, D. K., "FullScale Testing of Manufactured Homes in Naturally Occurring High Winds," Proceedings of Americas Conference on Wind Engineering 2001, June 4-6, 2001, Clemson, SC.

Richins, W. D., Larson, T. K., O'Brien, C. C., "INEEL Tests of Manufactured Homes in Extreme Environments," 2002 National Manufactured Housing Congress, Las Vegas, NV, April 2-4, 2002

Beaudoin, D. K., "Modeling and Analysis of Wind Pressure Distribution on a Manufactured Home," MS Thesis, Univ. of Wyoming, Dec. 2002

Richins, W. D, Larson, T. K., Lacy, J. M., "Windstorm Performance Testing of Modern Manufactured Homes," 2003 National Hurricane Conference, New Orleans, LA, April 14-18, 2003

Richins, W. D., Larson, T. K., O’Brien, C. C., Lacy, J. M., "Windstorm Design Software Development for Modern Manufactured Homes," 2003 National Congress for Manufactured and Modular Housing, Las Vegas, NV, April 22-24, 2003

Richins, W. D., Larson, T. K., Blakeley, J. E., Rahl, T. E., Twitchell, G. A., Kobbe, R. G., Crawford, A. L., and Pandey, A. K., "Lateral Load Testing of a Double-Section Manufactured Home - Test Report," INEEL Test Report, INEEL/EXT-03-00191, April 2003.

O'Brien, C. C., Richins, W. D., Larson, T. K., "INEEL Severe Weather Test Site in Wyoming," AAWE Newsletter, March 2003 
Richins, W. D., Larson, T. K., Blakeley, J. E., Rahl, T. E., Lacy, J. M., Twitchell, G. A., and Kobbe, R. G., "Natural Wind Testing of a Double-Section Manufactured Home - Test Report," INEEL Test Report in progress, Oct. 2005.

Richins, W. D., Larson, T. K., "Manufactured Home Testing in Naturally Occurring High Winds," in preparation for Journal of Architectural Engineering, 2005.

O'Brien, C. C., Richins, W. D., Larson, T. K., "INEEL Test Site Hopes to Reveal New Insight into the Performance of Manufactured Homes," Building Safety Journal, August 2003

Bafna, S. D., "A Novel Technique for the Analysis of Shear Walls within Manufactured Homes using the Finite Element Method," MS Thesis, Wash. State Univ., May 2004

"FElt: User's Guide and Reference Manual," Jason I. Gobat (Department of Applied Ocean Physics and Engineering, Woods Hole Oceanographic Institution) and Darren C. Atkinson (Department of Mathematics and Computer Science, Clark University), Computer Science Technical Report CS94-376, University of California, San Diego, 2000 